\title{
Microvesicles and exosomes in pulmonary hypertension
}

\author{
Rajamma Mathew', Thambi Dorai ${ }^{2}$ \\ 'Departments of Pediatrics and Physiology, New York Medical College, Valhalla, NY 10595, USA. \\ ${ }^{2}$ Deapertments of Urology and Biochemistry and Molecular Biology, New York Medical College, Valhalla, NY 10595, USA.
}

Correspondence to: Dr. Rajamma Mathew, Basic Science Building, New York Medical College, 15 Dana Road, Valhalla, NY 10595, USA. E-mail: rmathew@nymc.edu

How to cite this article: Mathew R, Dorai T. Microvesicles and exosomes in pulmonary hypertension. Vessel P/us 2020;4:11. http://dx.doi.org/10.20517/2574-1209.2019.35

Received: 23 Dec 2019 First Decision: 25 Feb 2020 Revised: 1 Apr 2020 Accepted: 14 Apr 2020 Published: 11 May 2020

Science Editor: Narasimham L. Parinandi Copy Editor: Jing-Wen Zhang Production Editor: Tian Zhang

\begin{abstract}
Pulmonary hypertension is a serious disorder with a high morbidity and mortality rate. The juxtaposition of endothelial cells and smooth muscle cells maintains vascular homeostasis. Vascular injury results in endothelial dysfunction, leading to impaired vascular relaxation, cell proliferation, and altered immune and metabolic states. In addition, injury induces pulmonary arterial endothelium and other cells to release increased levels of extracellular vesicles, including exosomes and microparticles that may be involved in enhancing the proliferation of apoptosisresistant smooth muscle cells. These extracellular vesicles carry proteins, lipids, RNA, miRNA, chemokines cytokines and modulate immune function, inflammation, embryogenesis, regenerative processes, and serve as intercellular messengers. Importantly, mesenchymal stem cells-derived extracellular vesicles exert inhibitory effects on inflammation and restore homeostasis. This article reviews the pathophysiological role of extracellular vesicles in pulmonary hypertension.
\end{abstract}

Keywords: Endothelial cells, extracellular vesicles, mesenchymal cells, pulmonary hypertension

\section{INTRODUCTION}

Pulmonary hypertension $(\mathrm{PH})$ is a serious complication of a number of systemic diseases including cardiovascular, respiratory and hematological disorders, autoimmune diseases, genetic mutations, and as yet unidentified causes. Based on the underlying disease, $\mathrm{PH}$ can be classified into five major groups. The term pulmonary arterial hypertension (PAH) is applied to diseases in group 1, which includes idiopathic and heritable PAH (IPAH, HPAH), and PAH associated with congenital heart defects, inflammation, autoimmune diseases and drug toxicity. A number of genetic mutations are also associated with PAH.

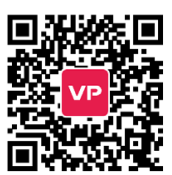




\section{Table 1. Pulmonary hypertension classification (based on Ref \#1)}

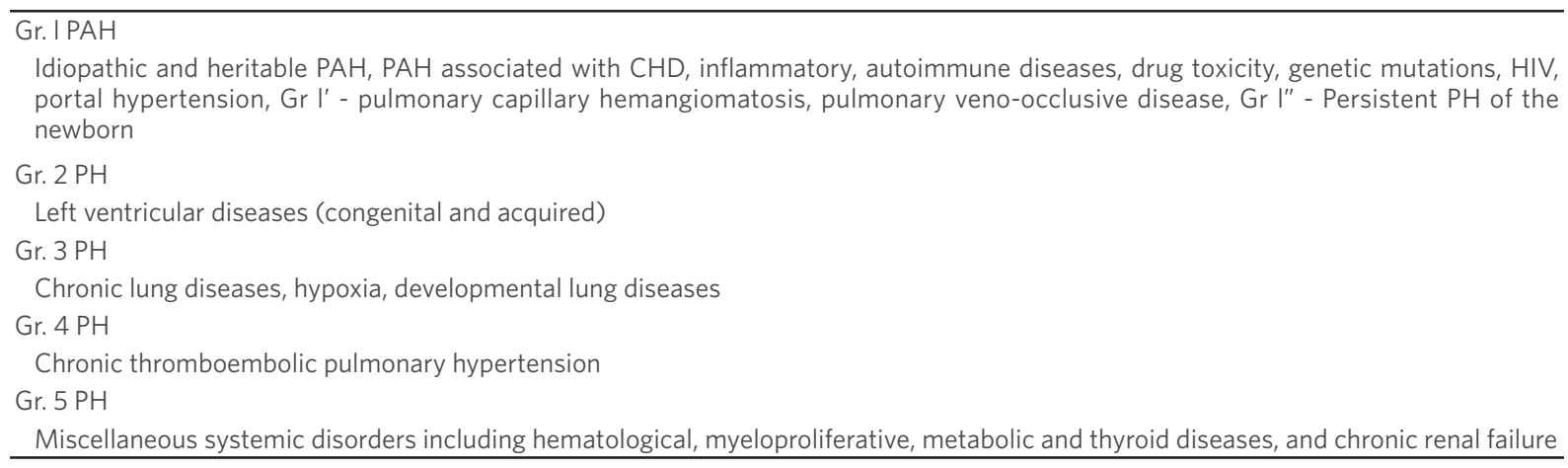

PAH: pulmonary arterial hypertension; $\mathrm{PH}$ : pulmonary hypertension

Pulmonary veno-occlusive disease and pulmonary capillary hemangiomatosis are assigned subcategory $1^{\prime}$ and persistent $\mathrm{PH}$ of the newborn is designated as $1^{\prime \prime}$. The remaining four groups are designated as $\mathrm{PH}$. Group 2 includes $\mathrm{PH}$ associated with left ventricular diseases and pulmonary venous hypertension. Included in group 3 are chronic lung diseases, alveolar hypoventilation disorders and developmental lung diseases while group 4 includes chronic thromboembolic PH. Finally, group 5 includes PH associated with miscellaneous diseases such as myeloproliferative, hematological, thyroid and renal diseases ${ }^{[1]}$ [Table 1].

During the sixth World Symposium on $\mathrm{PH}$, the mean pulmonary artery pressure threshold was reduced to $>20 \mathrm{mmHg}$ from $\geq 25 \mathrm{mmHg}$, and pulmonary vascular resistance maintained as $>3$ Wood units ${ }^{[2]}$. This change is based on the evaluation of 47 studies from 13 countries that showed normal mean pulmonary artery pressure rarely exceeded $20 \mathrm{mmHg}$, irrespective of age ${ }^{[3]}$. The survival time for patients with PAH (Gr. 1) without treatment is reported to be 2.8 years $^{[4]}$. Modern treatment has improved the quality of life and 3 -year survival in these patients is now around $58 \%-67 \%{ }^{[5,6]}$.

Despite such treatment, the underlying vascular pathology continues to worsen ${ }^{[7]}$. Regardless of the underlying disease, pulmonary endothelial cell (EC) disruption/dysfunction plays a pivotal role in the pathogenesis of $\mathrm{PH}$. ECs maintain vascular homeostasis and regulate vascular tone, cell permeability, inflammation, and coagulation through several mediators such as nitric oxide (NO), endotheliumderived hyperpolarization factor, endothelin-1 (ET-1), cell adhesion molecules, cytokines and chemokines. Endothelial dysfunction, alterations in the expression of NO, ET-1, caveolin-1, serotonin, inflammatory cytokines and chemokines, and disordered proteolysis of the extracellular matrix all contribute to the pathogenesis of $\mathrm{PAH}^{[8,9]}$. The increased expression of cytokines such as interleukin-1 (IL-1) and IL-6 ${ }^{[10,11]}$ and chemokines such as CX(3)CL1 (fractalkine) and CCL5, also known as RANTES ${ }^{[12,13]}$, have all been observed in both human and experimental PH. Furthermore, plexiform lesions contain perivascular infiltration with inflammatory $\mathrm{T}$ and $\mathrm{B}$ cells ${ }^{[14,15]}$. Disruption or dysfunction of endothelial caveolin-1 (a major protein constituent of caveolae) associated with the activation of proliferative molecules such as tyrosine tyrosine phosphorylated signal transducer and activator of transcription 3 (py-STAT3), B cell lymphoma-extra-large (Bcl-xL) and $\beta$-catenin leads to smooth muscle cell (SMC) proliferation, medial hypertrophy and $\mathrm{PH}^{[16,17]}$.

SMCs are a heterogeneous cell population which exhibit different proliferative, inflammatory, and extracellular matrix production changes during vascular remodeling. In addition, the extension of pericytes into non-muscularized arteries has been documented in $\mathrm{PH}^{[18]}$. Pericytes are heterogeneous cells in origin. The close interactions between pericytes and ECs are important for paracrine signaling involved in vascular development and stability. In addition, pericytes modulate immune responses ${ }^{[19]}$. It has recently been shown that the dysfunctional EC in IPAH may partly contribute to the increased pericyte coverage 
in distal pulmonary arteries, through the EC-derived fibroblast growth factor 2 (FGF-2) and IL- ${ }^{[20]}$. Pericyte-specific upregulation of CXCR (C-X-C chemokine receptor)- 7 and transforming growth factor- $\beta$ receptor II (TGF- $\beta$ RII) in patients with PAH are considered critical for their proliferation/migration capacities and myogenic potentials. During the early phase, pericyte numbers increase in a CXCL (C-X-C motif chemokine ligand)-12-dependent manner and later, the activation of the TGF- $\beta$ signaling pathway induces pericytes to differentiate into smooth muscle-like cells ${ }^{[21]}$. Furthermore, reduced endothelialpericyte interactions result in progressive loss of small vessels in PAH. Increased expression of pyruvate dehydrogenase kinase 4 (PDK4) gene and protein in PAH pericytes correlated with reduced mitochondrial metabolism, higher rates of glycolysis, and hyperproliferation. Reducing PDK4 levels improved endothelialpericyte interactions, restored mitochondrial metabolism, and reduced cell proliferation ${ }^{[22]}$. These studies underscore the importance of EC and pericyte interactions in maintaining vascular homeostasis.

The disruption/apoptosis of ECs and accompanying endothelial caveolin-1 loss followed by enhanced expression of caveolin-1 in SMCs, proliferation of antiapoptotic ECs and neointima formation have all been reported in experimental $\mathrm{PH}$ and human $\mathrm{PAH}^{[23-26]}$. In a monocrotaline $(\mathrm{MCT})+$ hypoxia model, the enhanced expression of caveolin-1 revealed the presence of tyrosine 14-phosphorylated caveolin-1 $\left(\mathrm{p}\right.$-cav-1) and the loss of polymerase 1 and transcription factor also known as cavin-1 ${ }^{[25]}$. Cavin-1 maintains the shape of caveolae and stabilizes caveolin-1 in caveolae. The loss of cavin-1 is indicative of the flattening of caveolar structure. Cavin-1 knockout mice exhibit pathological lung changes such as remodeled pulmonary vessels, $\mathrm{PH}$ and right ventricular hypertrophy (RVH). In addition, these mice have an altered metabolic phenotype with insulin resistance ${ }^{[27]}$. It is worth noting here that in cancer, p-cav-1 has been shown to inactivate the growth inhibitory function of the caveolin-1 scaffolding domain and facilitate cell migration ${ }^{[28-30]}$. These studies indicate that the disruption of endothelial caveolin-1 and dysfunction of SMC caveolin-1 participate in the progression of $\mathrm{PH}$. In addition, other factors such as vascular endothelial growth factor (VEGF), epidermal growth factor, transforming growth factor $\beta$ (TGF $\beta$ ), matrix metalloproteinases, bone morphogenic protein receptor type 2 (BMPR2) and Notch1 have all been implicated in the pathophysiology of $\mathrm{PAH}^{[31]}$. Thus, a large number of deregulated transcription factors and proliferative pathways participate in the pathobiology of $\mathrm{PH}$. Recent studies have shown that extracellular vesicles (EVs) may have an important role in the pathogenesis of $\mathrm{PH}$.

\section{EVs}

EVs have been isolated from body fluids such as blood, urine, saliva and cerebrospinal fluid. Initially EVs were thought to be a means for cells to get rid of unwanted components. Currently, they are identified as important mediators of intercellular communication. EVs participate in the exchange of lipids, proteins and genetic material between cells, modulate immune, inflammatory and regenerative processes, and maintain homeostasis. EVs are released from a variety of cells including platelets, erythrocytes, leukocytes, and ECs maintain their different compositions and function. Most cell types generate EVs that play important roles in various biological processes, including embryogenesis, tissue regeneration and immunomodulation. They regulate the transfer of biological information both locally as well as remotely ${ }^{[32-35]}$. EVs include exosomes (30-130 nm, in diameter), microparticles (MPs, also known as microvesicles, 100-1000 nm) and apoptotic bodies (50-4000 nm). Apoptotic bodies are generated following activation of the apoptotic pathway and cell death.

\section{Exosomes}

For exosome formation, endosomal membrane invagination captures cytosolic components within intraluminal vesicles. Early endosomes then mature into late endosomes and accumulate intraluminal vesicles, known as multivesicular bodies in their lumen. These multivesicular bodies either fuse with lysosomes for degradation or with the plasma membrane and are released into the extracellular space as exosomes $^{[36,37]}$ [Figure 1]. 


\section{Donor Cell}

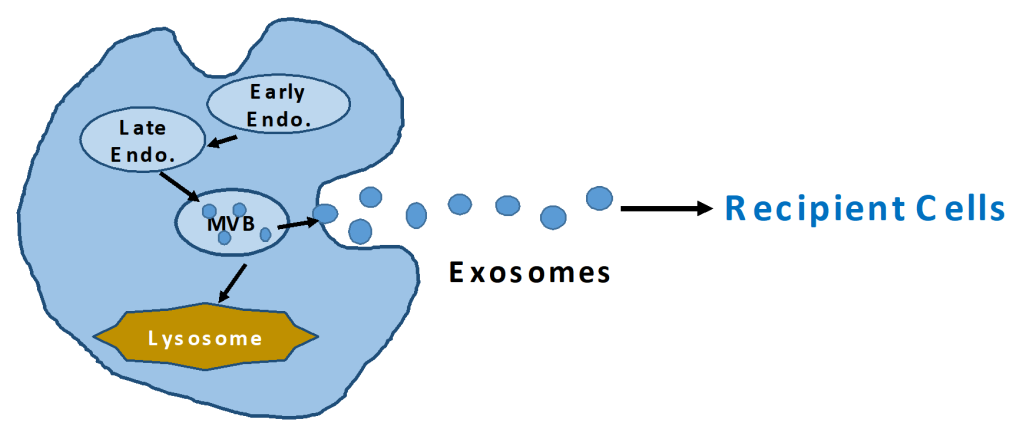

Figure 1. Early endosomes (Early Endo) mature into late endosomes (Late Endo) and accumulate intraluminal vesicles known as MVB. MVB release exosomes into the extra cellular space, or fuse with lysosome for degradation. These exosomes are then incorporated into recipient cells. MVB: multivesicular bodies

Reticulocytes were the first cells shown to release exosomes containing transferrin receptor during maturation ${ }^{[38]}$. The main components of exosome membranes are lipids and proteins enriched with lipid rafts. In addition, they contain mRNAs, microRNAs (miRNAs), and other non-coding RNAs. The interaction between the transmembrane proteins of exosomes and the signaling receptors of target cells could either be direct, or indirectly after fusion with the plasma membrane of recipient cells to deliver the content into the cytosol. In addition, exosomes internalized into recipient cells may merge into endosomes, undergo transcytosis, move across recipient cells and released into neighboring cells. Alternatively, endosomes fused with engulfed exosomes mature into lysosomes and undergo degradation ${ }^{[39]}$. EVs are engulfed into the cells via endocytosis. The lipid rafts, the known sites for endocytosis, are the specific microdomains within the plasma membrane that contain high concentrations of cholesterol and glycosphingolipids. Caveolins and flotillins are enriched with these lipid rafts. Interestingly, siRNAmediated knockdown of caveolin-1 and flotillin-1, but not clathrin heavy chain, results in the inhibition of EV internalization ${ }^{[40]}$. However, caveolin-1 localized in the plasma membrane negatively regulates exosome uptake, partly through the suppression of ERK1/2 signaling activation ${ }^{[41]}$. CAV1 gene knockout results in reduced caveolin-1 protein and impaired EV uptake. However, CAV1 knockout in mouse embryonic fibroblast cells resulted instead, in increased EV uptake ${ }^{[42]}$. Thus, EV uptake may depend on the cell type and its pathophysiological state. In addition, Rab proteins are essential regulators of EV transport ${ }^{[43]}$. Endothelial exosomes are also involved in vascular development as they incorporate and transfer Deltalike 4 (Dll4) to neighboring ECs, resulting in inhibition of notch signaling and increased vascular branch formation $^{[44]}$.

\section{MPs}

MPs are shed from various cell types as small fragments. In 1967, MPs shed during coagulation were regarded as platelet dust. Studies over the years have since shown that these MPs participate in cellular signaling, homeostasis, vascular injury and coagulation ${ }^{[45]}$. MPs are formed by the plasma membrane pinching off and encapsulating cytosolic components, and they maintain surface markers and receptors of the plasma membranes of the parent cells [Figure 2].

They efficiently exchange biological information between cells and thus, participate in intercellular communication. In the healthy state, circulating MPs originate mainly from platelets and, to a smaller extent, from leukocytes, erythrocytes, granulocytes, monocytes, lymphocytes and ECs. Increased circulating MPs are biomarkers of vascular injury and inflammation. Cells exposed to different stimuli such as shear stress, physical agonists, pro-apoptotic stimuli or injury release MPs contributing to EC dysfunction in cardiovascular diseases ${ }^{[46]}$. Stimulation of ECs by cytokines, reactive oxygen species, plasminogen activation inhibitor, thrombin or C-reactive protein leads to the formation of endothelial MPs. 


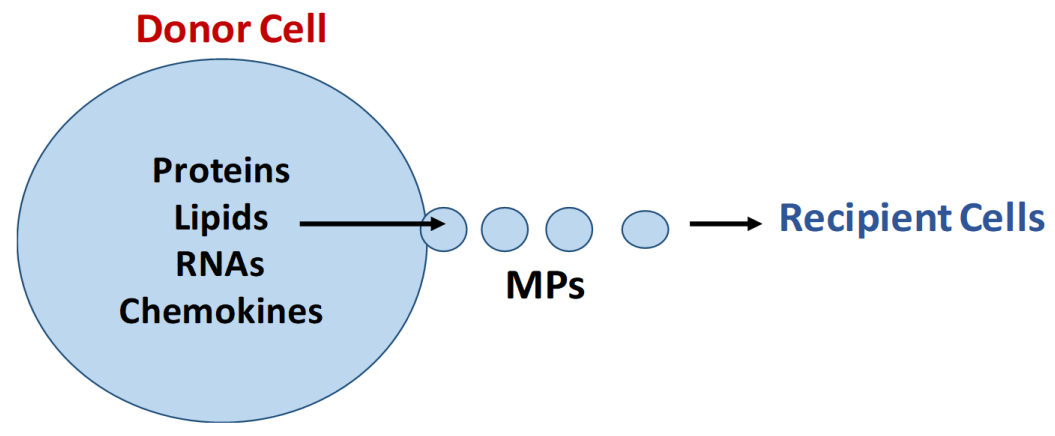

Figure 2. MPs are formed by the plasma membrane pinching off and encapsulating cytosolic components. MPs: microparticles

MPs play an important role in inflammation, EC function and cellular survival ${ }^{[47]}$. Circulating MPs impair the atheroprotective function of ECs, in part, by decreasing NO synthesis. Increased levels of circulating MPs are useful biomarkers of vascular injury and a predictor of adverse cardiovascular events and mortality in patients with atherosclerotic disease. Atherosclerotic lesions contain a large number of MPs of leukocyte, SMC, EC and red blood cell origin ${ }^{[48]}$, and even patients with subclinical atherosclerosis exhibit increased levels of circulating leukocyte-derived $\mathrm{MPs}^{[49]}$.

In addition, MPs promote coagulation, inflammation and alter angiogenesis and apoptosis in ECs. Studies indicate that MPs induce EC dysfunction by disrupting NO release. Endogenous NO inhibits the release of endothelial MPs upon stimulation with C-reactive protein through a tetrahydrobiopterindependent mechanism ${ }^{[50]}$. Endothelial MPs deliver C-reactive protein and participate in inflammation and coagulation $^{[51]}$. MPs from T- lymphocytes depress endothelial nitric oxide synthase (eNOS) activity and increase oxidative stress in ECs; however, T-lymphocytes carrying morphogen sonic hedgehog increase NO production ${ }^{[46]}$. Furthermore, the release of MPs carrying lytic complement C5b-9 complex protects ECs from complement-induced lysis. MPs from leukocytes stimulate pro-inflammatory genes in ECs in vitro, resulting in the release of cytokines and leukocyte-EC adhesion molecules. On the other hand, MPs from polymorphonuclear leukocytes contain annexin-1, a functionally active anti-inflammatory protein. In vivo, annexin-1 inhibits the interaction between leukocytes and $\mathrm{ECs}^{[52]}$. In in vitro studies, the inhibition of endothelial MP release has been shown to induce caspase- 3 accumulation, leading to cellular apoptosis. Thus, endothelial MP release could protect EC apoptosis by reducing caspase-3 levels ${ }^{[53]}$. Pulmonary microvascular ECs have higher levels of basal cAMP and pulmonary ECs release cAMP containing EVs. These EVs are thought to facilitate compartmentalized cAMP signals and thus, may strengthen the endothelial barrier ${ }^{[54]}$. In vitro studies have shown that MPs derived from platelets stimulate cell proliferation, migration, and tube formation in ECs. In addition, metalloproteinases contained in endothelial MPs regulate proteolytic activity on the matrix and elicit angiogenesis. Furthermore, MPs derived from endothelial progenitor cells may induce apoptosis-resistant cell proliferation ${ }^{[55]}$. MPs contain the cell surface protein and cyotoplasmic components of the original cell, and exhibit phosphatidylserine on the surface that accounts for their procoagulant character. MPs from T cells induce EC dysfunction by altering NO and prostacyclin pathways. T-lymphocyte-derived MPs reduce eNOS expression and vascular relaxation, and exhibit increased expression of caveolin-1 ${ }^{[56]}$.

EVs participate in physiological as well as pathological conditions depending on their cargo. EV biogenesis is dysregulated in pathological conditions. Release of EVs can induce inflammation, angiogenesis and thrombosis, and are implicated in many diseases such as cancer, chronic obstructive pulmonary disease, atherosclerosis and $\mathrm{PH}$. During degranulation, activated polymorphonuclear leukocyte-derived exosomes $\left(\mathrm{CD}{ }^{+} / \mathrm{CD}_{66} \mathrm{~b}^{+}\right)$acquire surface-bound neutrophil elastase that is resistant to $\alpha 1$-antitrypsin $(\alpha 1 \mathrm{AT})$. In chronic obstructive pulmonary disease and bronchopulmonary dysplasia (BPD), polymorphonuclear 
leukocyte-derived exosomes acquire surface-bound elastase that degrade extracellular matrix ${ }^{[57]}$. In sickle cell disease, inflammasome-dependent shedding of platelet EVs carrying IL-1 $\beta$ and caspase- 1 activate neutrophils and other vascular cells to form large platelet-neutrophil aggregates that occlude pulmonary arteries. The level of circulating platelet EVs correlate with disease severity. Increased circulating platelets and erythroid MPs were observed in untreated children with sickle cell disease; hydroxyurea therapy, however, normalized MP levels ${ }^{[58,59]}$. In vitro studies have shown that high arterial stress results in platelet activation and release of prothrombogenic EVs in the blood ${ }^{[60]}$. In cell culture studies, platelet MPs have been shown to induce SMC proliferation in a platelet derived growth factor-independent manner ${ }^{[61]}$. In addition, circulating platelet-derived EVs induced increased production of cytokines (IL-1, IL-6, and IL-8), leading to immune modulation, endothelial dysfunction and remodeling. In contrast, neutrophil-derived EVs enhance the biosynthesis of specialized pro-resolving mediators ${ }^{[62]}$. MPs from patients with metabolic syndrome decrease NO production in ECs in culture, independent of oxidative stress. Furthermore, injection of MPs in mice resulted in reduced eNOS synthesis and impaired vascular relaxation ${ }^{[63]}$. In addition, tissue factor containing MPs are proinflammatory mediators between increased glucose levels and diabetic vasculopathy ${ }^{[64]}$. In cancer, EVs promote tumor growth, metastasis and resistance to therapy; and the activation of oncogene signaling pathway can increase EV production. These EVs transfer oncoproteins and facilitate tumor angiogenesis, immunosuppression and metastasis ${ }^{[65,66]}$. In vitro studies have shown large EVs carrying caveolin-1 in cancer cells to be involved in metastasis ${ }^{[67]}$. Thus, the function of MPs depends on the cell types that they originate from and their pathophysiological state.

Mesenchymal stem cells (MSC) are the best cell types for tissue regenerative therapies. They can be readily derived, propagated and differentiated into a variety of cell types. They modulate several biological functions such as tissue repair, downregulation of inflammatory responses, and modulation of the immune system. MSC-derived exosomes have protective effects on ischemia-reperfusion injury via inhibition of cell apoptosis and inflammatory responses ${ }^{[68,69]}$. Furthermore, treatment with multipotent stem cells showed strong regenerative capabilities in animal models of myocardial ischemia ${ }^{[70]}$, stroke ${ }^{[71]}$, and diabetes $^{[72]}$. Recent studies have suggested that MSC-derived EVs containing miRNAs might promote cell and tissue repair, and regeneration ${ }^{[73]}$. Similar to the biological activities of MSC, MSC-derived exosomes recover and regenerate the damaged tissues and restore homeostasis ${ }^{[74]}$. MSC-exosomes reduce oxidative stress and prevent adverse remodeling in hearts subjected to ischemia-perfusion ${ }^{[75]}$; and placental MSCderived exosomes promote new blood vessel formation and angiogenesis within the placenta under low oxygen conditions ${ }^{[76]}$. Interestingly, female bone marrow derived MSCs exhibit higher therapeutic efficacy compared with male MSCs in reducing neonatal hyperoxia-induced lung inflammation, vascular remodeling and $\mathrm{PH}$ in a rat model of $\mathrm{BPD}$. Female MSCs express higher levels of VEGF and IL-10, and are better in attenuating $\mathrm{PH}$ and improving pulmonary vascular remodeling. The effects on angiogenesis and alveolarization however, were similar in female and male MSC treatment ${ }^{[77]}$. In an ischemia-reperfusion injury model, female MSC infusion revealed a greater degree of myocardial recovery compared to male MSC. The protective effect of female MSCs appears to be related to lower levels of TNFR ${ }^{[78]}$. In addition, $17 \beta$-estradiol-treated cardiac stem cells increased the expression of VEGF and SDF-1, and decreased caspase 3 resulting in improved myocyte survival after acute ischemia perfusion injury ${ }^{[79]}$. These studies suggest that the superior cell survival effect of female MSCs may be dependent on estrogen levels. In contrast, male muscle-derived stem cells display better cartilage regeneration potential compared with their female counterparts ${ }^{[80]}$. Thus, these gender differences may be tissue-specific and female MSCs appear to provide better protection in cardiovascular and lung diseases.

\section{PULMONARY HYPERTENSION AND EXTRACELLULAR VESICLES}

Altered immunity, platelet activation, vascular inflammation, endothelial dysfunction and thromboembolic complications are well known features of PH. Platelet MPs have been shown to roll over ECs to deliver CCL5 ${ }^{[81]}$. Importantly, CCL5 is a chemo-attractant for monocytes and T cells. In severe PAH, ECs 
were found to be the major source of CCL5 ${ }^{[13]}$. Circulating MPs have also been shown to stimulate ICAM expression in pulmonary arterial ECs during the late stage in a Sugen + hypoxia model of $\mathrm{PH}^{[82]}$. Increased levels of platelet-derived MPs, defined as $\mathrm{CD} 31^{+} / \mathrm{CD} 41^{+}$, and endothelium-derived MPs as $\mathrm{CD} 31^{+} / \mathrm{CD} 41$ ,were observed in IPAH, HPAH and "associated" PAH compared to controls ${ }^{[83]}$. Recent studies have shown increased levels of circulating MPs of platelet $\left(\mathrm{CD}_{31} 1^{+} / 61^{+}\right)$, leukocyte $\left(\mathrm{CD} 11 \mathrm{~b}^{+}\right)$and endothelial $\left(\mathrm{CD}_{2} \mathrm{E}^{+}\right)$ origin in patients with PH. Furthermore, significantly increased endothelial MP levels were detected in patients with thrombo-embolic $\mathrm{PH}$ compared to non-embolic patients, indicating increased endothelial dysfunction in the former ${ }^{[84]}$. In addition, elevated levels of endothelial MPs, but not leukocyte MPs, prior to treatment are associated with adverse clinical events. Increased $\mathrm{CD} 62 \mathrm{e}^{+}$levels are associated with an inflammatory state ${ }^{[85]}$. EVs from animals with PH induce endothelial dysfunction. MPs from hypoxic rats impair EC-dependent relaxation in pulmonary arteries and aorta via reducing NO production and increasing oxidative stress ${ }^{[86]}$. MPs bearing active tissue factor and CD105 (endoglin) were reported to be elevated in patients with PAH. Interestingly, in patients with $\mathrm{PAH}$, a further increase in endotheliumderived CD105 MPs was observed in pulmonary arterial blood compared with venous blood. Furthermore, patients in functional class III and IV were found to have higher levels of MPs bearing active tissue factor $^{[87]}$. In addition, increased levels of circulating endothelial (CD62E-E-selectin) and CD3 (T cell)derived EVs were observed in patients with different forms of $\mathrm{PH}^{[8]}$. Interestingly, in vitro studies have revealed that upon exposure to injury, pulmonary arterial ECs release increased amounts of exosomes that induce apoptosis-resistant pulmonary arterial SMC proliferation ${ }^{[89]}$.

Disturbed blood flow has been shown to acutely induce both endothelial activation and apoptosis, resulting in the release of MPs from activated $\left(\mathrm{CD}_{2} \mathrm{E}^{+}\right)$and apoptotic $\left(\mathrm{CD} 31^{+} / \mathrm{CD} 42 \mathrm{~b}^{-}\right) \mathrm{ECs}{ }^{[90]}$. Increased endothelial MPs have been reported in adult patients with congenital heart defects (atrial and ventricular septal defects) especially with 'associated' PAH. These endothelial MPs may contribute to inflammation, leading to endothelial dysfunction, impaired vasodilatation and inhibit angiogenesis via p39 $\mathrm{MAPK}^{[91]}$. However, no differences in endothelial MP expression were observed in children with congenital heart defects with or without associated $\mathrm{PAH}^{[92]}$.

Apoptotic ECs release exosomes containing tumor susceptibility gene 101 and translationally controlled tumor protein (TCTP) with antiapoptotic function. Vascular SMCs, upon exposure to these nanovesicles, exhibit increased resistance to apoptosis and ERK1/2 activation. Silencing TCTP blocks the resistance to apoptosis and ERK1/2 activation ${ }^{[93]}$. TCTP is also a potent mediator of inflammation. In patients with IPAH, HPAH and in a Sugen + hypoxia model, increased levels of TCTP were found in blood outgrowth EC. Knockdown of TCTP resulted in increased apoptosis in these cells in in vitro studies. These authors have further shown increased levels of blood outgrowth EC-derived exosomes and MPs in patients with PAH associated with BMPR2 mutation ${ }^{[94,95]}$. Upregulation of miR143-5p has been reported in pulmonary arterial SMCs from experimental PH and human PAH. Pulmonary arterial SMC-derived exosomes exhibited enhanced expression of miR143-5p, which induced pro-migratory and pro-angiogenic effects on $\mathrm{ECs}^{[96]}$.

CD39, an ectonucleoside triphosphate diphosphohydrolase, is expressed in the lipid raft domain in plasma membranes of cells including ECs, monocytes and lymphocytes, and functions as an anti-inflammatory and thromboregulatory factor. The absence of $\mathrm{CD} 39$ on ECs results in increased susceptibility of ECs to stimulation ${ }^{[97]}$. Importantly, ECs in IPAH exhibit downregulation of CD39. Furthermore, suppression of CD39 in in vitro studies results in apoptosis resistant pulmonary arterial ECs, and an increased ATP niche that stimulates SMC proliferation and migration ${ }^{[98]}$. Visovatti et al. ${ }^{[99]}$ reported the presence of increased circulating endothelial and platelet MPs with CD39 on the surface in patients with IPAH. In addition, ATPase and ADPase activities were increased. In PAH, endothelial dysfunction/disruption and/ or apoptosis is the underlying pathological event. Therefore, it is likely that CD39 is lost from ECs, which 
could then facilitate proliferation of anti-apoptotic ECs. The loss of endothelial caveolin-1, PECAM-1, vWF and vascular endothelial cadherin, which is indicative of endothelial disruption, has been described in experimental and human PAH ${ }^{[16,24,100]}$. Furthermore, increased levels of endothelial MPs carrying vascular endothelial cadherin and PECAM-1 were shown to be associated with hemodynamic severity of PAH ${ }^{[101]}$. In addition, BMPR2 loss has been reported in experimental $\mathrm{PH}$ and in patients with IPAH without the BMPR2 mutation, and to a lesser degree, in patients with "associated" $\mathrm{PAH}^{[102,103]}$. Interestingly, the loss of endothelial caveolin-1 and oxidative stress leads to reduced BMPR2 expression, increased TGFßderived Smad 2/3 signaling and pulmonary vascular remodeling ${ }^{[104]}$. Oliveira et al ${ }^{[105]}$ recently showed that in the Sugen + hypoxia model of PH in rats and human PAH, endothelial caveolin-1 loss accompanied by increased plasma levels of caveolin-1 EVs and TGF $\beta$, indicating that the endothelial caveolin-1 loss contributes to increased TGF $\beta$ signaling, leads to EC proliferation, vascular remodeling and PAH. Caveolin-1 appears to be a plasma biomarker of vascular injury and a key determinant of TGF $\beta$-induced vascular remodeling. It is possible then that the increased levels of EVs containing caveolin-1 in plasma could, in part, be responsible for enhanced expression of caveolin-1 in SMCs observed in IPAH, HPAH and $\mathrm{PAH}$ associated with drug toxicity and congenital heart defects ${ }^{[23,24,100,106]}$.

Recent studies have shown that human pulmonary arterial ECs can efficiently incorporate EVs transmitted by human pulmonary arterial SMCs and translate their mRNA cargo. These EVs enriched in Zeb1 and TGF- $\beta$ superfamily ligands contribute to endothelial mesenchymal transition (EndMT), thus facilitating disease progression ${ }^{[107]}$. However, partial EndMT is a physiological process necessary for angiogenesis. In partial EndMT, ECs do not separate from their neighboring cells ${ }^{[108]}$. Figure 3 (as shown on page 9) depicts the inter-relationship between ECs and SMCs, and the role played by EVs in PH.

Interestingly, cigarette smoking results in the release of endothelial EVs with spermine enrichment both on the surface as well as in the cytosol and activates a $\mathrm{Ca}^{2+}$-sensing receptor leading to pulmonary vasoconstriction, SMC proliferation and $\mathrm{PH}^{[109]}$. These results strongly support endothelial injury and disruption underlying the release of EVs. Depending on the cargo, EVs participate in EC-SMC crosstalk in physiological or pathological conditions.

\section{PH, MSC AND MESENCHYMAL EVS}

A number of studies have shown the beneficial effects of MSC therapy in experimental models of PH. Intravenous treatment with adipose-derived MSCs improved MCT-induced PH in rats. In addition, adipose-derived MSCs in co-culture with MCT-treated human pulmonary arterial ECs exhibit increased cell proliferation and expression of $\mathrm{VEGF}^{[110]}$. Bone marrow-derived MSCs over-expressing eNOS attenuated MCT-induced PH in rats ${ }^{[111]}$, and MSCs expressing increased hemoxygenase (HO)-1 reversed hypoxia-induced $\mathrm{PH}$ in mice ${ }^{[112]}$. In addition, transplantation with bone marrow-derived MSCs transduced with prostacyclin synthase, and therapy with adiponectin gene modified adipose MSCs significantly attenuated MCT-induced $\mathrm{PH}, \mathrm{RVH}$, pulmonary vascular thickening and survival in rats. In in vitro studies, the inhibitory effect of adiponectin on the proliferation of pulmonary arterial SMCs obtained from rats with MCT-induced PH was shown to be dependent on the regulation of the AMPK/BMP/Smad pathway $^{[13,114]}$. Interestingly, intravenous administration of bone marrow-derived MSCs from donor rats with MCT-induced PH to the recipient rat with MCT-induced PH resulted in attenuation of PH and RVH, and normalization of right ventricular function. Bone marrow-derived MSCs from MCT rats produced more VEGF compared to controls ${ }^{[15]}$. In addition, adipose tissue-derived MSC therapy in rats with shunt flow-induced hyperkinetic PAH was attenuated via increased expression of hepatocyte growth factor and eNOS promoting angiogenesis in the injured lungs ${ }^{[116]}$.

Importantly, female bone marrow-derived MSCs were found to attenuate MCT-induced PH and RVH in mice better than male MSCs. Female MSCs had increased expression of glyceraldehyde-3-phospahte 


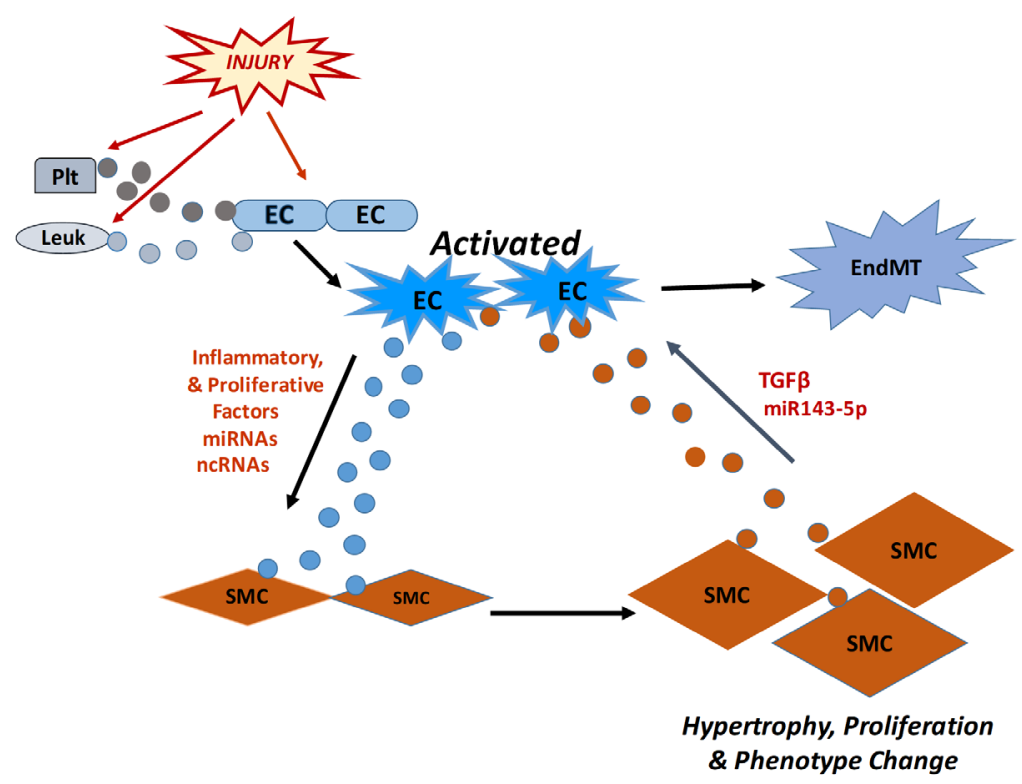

Figure 3. This figure depicts the possible mechanism of injury resulting in dysregulation of a number of vascular and inflammatory cells. Injury (inflammatory, oxidant, drug toxicity, increased pulmonary flow) activates Plt, Leuk and EC to produce increased amounts of EVs. EVs from platelets and leukocytes induce EC dysfunction. Endothelial EVs contain inflammatory and proliferative factors, and miRNAs are incorporated in SMCs, leading to hypertrophy, proliferation and phenotype change. These SMCs produce EVs containing TGF $\beta$, miRNAs and other factors that are incorporated into ECs, leading to EndMT. EC: endothelial cell; EVs: extracellular vesicles; SMCs: smooth muscle cells; EndMT: endothelial mesenchymal transition; Plt: platelets; Leuk: leukocytes; TGF $\beta$ : transforming growth factor $\beta$

dehydrogenase that regulates $\left(\mathrm{Ca}^{2+}\right)$ i signal associated function, which might be responsible for the superior function of female bone marrow-derived MSCs ${ }^{[117]}$. Furthermore, in an ischemia-reperfusion model, rat hearts treated with female MSCs demonstrated significantly greater recovery of left ventricular pressure compared to male MSC treated hearts. Importantly, male MSCs produced higher levels of TNF $\alpha$ and less VEGF than female MSCs ${ }^{[118]}$.

EVs from plasma and lung homogenates from mice with MCT-induced PH have been shown to induce $\mathrm{PH}$ and $\mathrm{RVH}$ in healthy mice. Interestingly, exosomes but not microvesicles from MCT-mice injured wild type mice; MSC-induced exosomes also prevented and reversed MCT-induced PH. Furthermore, exosomes from MCT-treated mice and patients with IPAH revealed increased expression of miRs-19b, $-20 \mathrm{a},-20 \mathrm{~b}$, and -145 . In contrast, MSC-exosomes exhibited increased levels of anti-proliferative and antiinflammatory miRs $(-34 \mathrm{a},-122 .-124,-127)^{[119]}$. Chen et al. ${ }^{[120]}$ have shown that both bone marrow-derived MSCs and MSC-EVs ameliorated MCT-induced PH and RVH, indicating that a cell free approach to stem cell therapy is effective. In addition, adipose-derived exosomes have been shown to transfer miR125a to ECs to promote angiogenesis by suppressing angiogenic inhibitor Dll4 and facilitate repair ${ }^{[121]}$. Reninangiotensin involvement in the pathogenesis of $\mathrm{PH}$ is well documented. Liu et al. ${ }^{[122]}$ have reported that bone marrow-derived MSC-microvesicles attenuated MCT-induced $\mathrm{PH}$ and $\mathrm{RVH}$ in rats accompanied by increased levels of ACE2 mRNA in lung tissue, increased plasma levels of Ang-(1-7) and decreased ACE compared with controls. Interestingly, the administration of adipose-derived MSC-EVs was shown to inhibit neointima formation in the vein graft model, accompanied by a significant decrease in the expression of IL-6, monocyte chemoattractant protein-1 and phosphorylation of Akt, Erk $1 / 2^{[123]}$. In mice with hypoxia-induced $\mathrm{PH}$, intravenous treatment with MSC-derived exosomes attenuated $\mathrm{PH}$ and $\mathrm{RVH}$, reduced STAT3 activation and upregulated the miR-17 superfamily of miRNAs. In addition, treatment with MSC exosomes increased the level of miR204. It is worth noting here that the expression of miR204 in the lungs is low in patients with PAH. These authors have further shown in in vitro studies that the activation 
of py-STAT3 in human pulmonary arterial SMCs in response to hypoxia is inhibited by exosomes derived from the human umbilical cord ${ }^{[124]}$. Klinger et al..$^{[125]}$ have recently reported the prevention and reversal of the Sugen+ hypoxia model of PH in rats by MSC EVs. Similar to the cancer phenotype, in PAH, cells undergo a metabolic shift towards glycolysis and lactic acid formation which enables sustained ATP production and uncontrolled cell growth. MSC exosomes increase glucose oxidation and prevent a shift to glycolysis and mitochondrial damage. In addition, exosomes inhibit SIRT4 expression upstream of pyruvate dehydrogenase and glutamate dehydrogenase that contribute to the improvement of mitochondrial function ${ }^{[126]}$. Thus, MSC-derived EVs can have beneficial effects on the pathophysiology of PH and mitochondrial function.

$\mathrm{PH}$ is a frequent and serious complication in preterm infants with BPD, a chronic lung disease. Treatment with conditioned media from cultured mouse bone marrow-derived MSCs showed significant improvement in hyperoxia-induced BPD in mice. It reversed hyperoxia-induced lung parenchymal pathological changes and $\mathrm{PH}^{[127]}$. Chang et al. ${ }^{[128]}$ treated nine preterm infants (gestational age $25.3 \pm 0.9$ weeks) with intratracheal transplantation of human umbilical cord blood-derived MSCs. At 7 days after treatment, these infants had no adverse effects, and the severity of BPD was observed to be low. In addition, tracheal aspirates revealed lower levels of IL-6, IL-8, metalloproteinase-9, TNF $\alpha$ and TGF $\beta 1$. These studies showed the beneficial effects of MSCs on lung development.

In summary, EVs play a significant role in the pathophysiology of $\mathrm{PH}$. Under normal conditions, EVs produced by different cells modulate immune responses, participate in intercellular communication and maintain homeostasis. Increased levels of EVs observed in $\mathrm{PH}$ are indicative of endothelial injury. These EVs facilitate cell proliferation, inflammation, and progression of the disease. MSCs and MSC-derived EVs are capable of modulating immune responses, repairing injured tissues and have regenerative properties. The beneficial effects of MSCs and MSC-EVs, including some genetically modified MSCs have been reported in several experimental models of PH. Treatment with MSC-EVs (naïve or genetically modified) may have an advantage over cell therapy.

\section{DECLARATIONS}

\section{Acknowledgments}

This work was supported in part by the CMREF (Cardiovascular Medical Research Education Fund) to Rajamma Mathew.

\section{Authors' contributions}

Written the paper: Mathew R

Contributed to discussion: Dorai $\mathrm{T}$

\section{Availability of data and materials}

Not applicable.

\section{Financial support and sponsorship}

None.

\section{Conflicts of interest}

All authors declared that there are no conflicts of interest.

\section{Ethical approval and consent to participate}

Not applicable. 


\section{Consent for publication}

Not applicable.

\section{Copyright}

(c) The Author(s) 2020.

\section{REFERENCES}

1. Simonneau G, Gatzoulis MA, Adatia I, Celermajer D, Denton C, et al. Updated clinical classification of pulmonary hypertension. J Am Coll Cardiol 2013;62:D34-41.

2. Simonneau G, Montani D, Celermajer DS, Denton CP, Gatzoulis MA, et al. Haemodynamic definitions and updated clinical classification of pulmonary hypertension. Eur Respir J 2019;53:1801913.

3. Kovacs G, Berghold A, Scheidl S, Olschewski H. Pulmonary arterial pressure during rest and exercise in healthy subjects: a systematic review. Eur Respir J 2009;34:888-94.

4. D’Alonzo GE, Barst RJ, Ayers SM, Bergofsky EH, Brundage BH, et al. Survival in patients with primary pulmonary hypertension. Results from a national prospective registry. Ann Intern Med 1991;115:343-9.

5. Humbert M, Sitbbon O, Chaouat A, Bertocchi M, Habib G, et al. Survival in patients with idiopathic, familial, and anorexigen-associated pulmonary arterial hypertension in modern management era. Circulation 2010;122:156-63.

6. Thenappan T, Shah SJ, Rich S, Gomberg-Maitland M. A USA-based registry for pulmonary arterial hypertension: 1982-2006. Eur Respir J 2007;30:1103-10.

7. Pogoriler JE, Rich S, Archer SL, Husain AN. Persistence of complex vascular lesions despite prolonged prostacyclin therapy of pulmonary arterial hypertension. Histopathology 2012;61:597-609.

8. Humbert M, Morrell NW, Archer SL, Stenmark KR, MacLean MR, et al. Cellular and molecular pathobiology of pulmonary arterial hypertension. J Am Coll Cardiol 2004;43:13S-24.

9. Mathew R. Inflammation and pulmonary hypertension. Cardiol Rev 2010;18:67-72.

10. Humbert M, Monti G, Brenot F, Sitbon O, Portier A, et al. Increased interleukin-1 and interleukin-6 serum concentrations in severe primary pulmonary hypertension. Am J Respir Crit Care Med 1995;151:1628-31.

11. Bhargava A, Kumar A, Yuan N, Gewitz MH, Mathew R. Monocrotaline induces interleukin-6 mRNA expression in rat lungs. Heart Dis 1999;1:126-32.

12. Balabanian K, Foussat A, Dorfmüller P, Durand-Gasselin I, Capel F, et al. CX (3) C chemokine fractalkine in pulmonary arterial hypertension. Am J Respir Crit Care Med 2002;165:1419-25.

13. Dorfmüller P, Zarka V, Durand-Gasselin I, Monti G, Balabanian K, et al. Chemokine RANTES in severe pulmonary arterial hypertension. Am J Respir Crit Care Med 2002;165:534-9.

14. Tuder RM, Groves B, Badesch DB, Voelkel NF. Exuberant endothelial cell growth and elements of inflammation are present in plexiform lesions of pulmonary hypertension. Am J Pathol 1994;144:275-85.

15. Stacher E, Graham BB, Hunt JM, Gandjeva A, Groshong SD, et al. Modern age pathology of pulmonary arterial hypertension. Am J Respir Crit Care Med 2012;186:261-72.

16. Huang J, Wolk JH, Gewitz MH, Mathew R. Caveolin-1 expression during the progression of pulmonary hypertension. Exp Biol Med 2012;237:856-65.

17. Huang J, Frid M, Gewitz MH, Fallon JT, Stenmark K, et al. Hypoxia-induced pulmonary hypertension and chronic lung disease: caveolin-1 dysfunction an important underlying feature. Pulm Circulation 2019;9:2045894019837876.

18. Stenmark KR, Frid MG, Graham BB, Tuder RM. Dynamic and diverse changes in the functional properties of vascular smooth muscle cells in pulmonary hypertension. Cardiovasc Res 2018;114:551-64.

19. Harrell CR, Markovic BS, Fellabaum C, Arsenijevic A, Djonov V, et al. Molecular mechanisms underlying therapeutic potential of pericytes. J Biomed Sci 2018;25:21.

20. Ricard N, Tu L, Le Hiress M, Huertas A, Phan C, et al. Increased pericyte coverage mediated by endothelial-derived fibroblast growth factor-2 and interleukin-6 is a source of smooth muscle-like cells in pulmonary hypertension. Circulation 2014;129:1586-97.

21. Bordenave J, Tu L, Berrebeh N, Thuillet R, Cumont A, et al. Lineage tracing reveals the dynamic contribution of pericytes to the blood vessel remodeling in pulmonary hypertension. Arterioscler Thromb Vasc Biol 2020;40:766-82.

22. 22. Yuan K, Shao NY, Hennigs JK, Discipulo M, Orcholski ME, et al. Increased pyruvate dehydrogenase kinase 4 expression in lung pericytes is associated with reduced endothelial-pericyte interactions and small vessel loss in pulmonary arterial hypertension. Am J Pathol 2016;186:2500-14.

23. Huang J, Wolk JHG, Gewitz MH, Loyd JE, West J, et al. Enhnaced caveolin-1 expression in smooth muscle cells: possible prelude to neointima formation. World J Cardiol 2015;7:671-54.

24. Mathew R, Huang J, Katta UD, Krishnan U, Sandoval C, et al. Immunosuppressant-induced endothelial damage and pulmonary hypertension. J Pediatr Hematol Oncol 2011;33:55-8.

25. Huang J, Mathew R. Loss of cavin1 and expression of p-Caveolin-1 in pulmonary hypertension: possible Role in Neointima Formation. World J Hypertension 2019;9:17-29.

26. Sakao S, Taraseviciene-Stewart L, Lee D, Wood K, Cool D, et al. Vascular endothelial growth factor receptor blockade by SU5416 
combined with pulsatile shear stress causes apoptosis and subsequent proliferation of apoptosis-resistant endothelial cells. Chest 2005;128:610S-1.

27. Swärd K, Sadegh MK, Mori M, Erjefält JS, Rippe C. Elevated pulmonary arterial pressure and altered expression of Ddah1 and Arg1 in mice lacking cavin-1/PTRF. Physiol Rep 2013;1:e00008.

28. Williams TM, Lisanti MP. Caveolin-1 in oncogenic transformation, cancer, and metastasis. Am J Physiol Cell Physiol 2005;288:C494-506.

29. Joshi B, Strugnell SS, Goetz JG, Kojic LD, Cox ME, et al. Phosphorylated caveolin-1 regulates Rho/ROCK-dependent focal adhesion dynamics and tumor cell migration and invasion. Cancer Res 2008;68:8210-20.

30. Núñez-Wehinger S, Ortiz RJ, Díaz N, Díaz J, Lobos-González L, et al. Caveolin-1 in cell migration and metastasis. Curr Mol Med 2014;14:255-74.

31. Schermuly RT, Ghofrani HA, Wilkins MR, Grimminger F. Mechanisms of disease: pulmonary arterial hypertension. Nat Rec Cardiol 2011;8:443-55.

32. van Niel G, D'Angelo G, Raposo G. Shedding light on the cell biology of extracellular vesicles. Nat Rev Cell Mol Biol 2018;19:213-28.

33. Slomka A, Urban SK, Lukacs-Kornek V, Żekanowska E, Kornek M. Large extracellular vesicles: have we found the holy grail of inflammation? Front Immunol 2018;9:2723.

34. Yáñez-Mó M, Siljander PR, Andreu Z, Zavec AB, Borràs FE, et al. Biological properties of extracellular vesicles and their physiological functions. J Extracell Vesicles 2015;4:27066.

35. Boulanger CM, Loyer X, Rautou PE, Amabile N. Extracellular vesicles in coronary artery disease. Nat Rev Cardiol 2017;14:259-72.

36. Colombo M, Raposo G, Théry C. Biogenesis, secretion, and intercellular interactions of exosomes and other extracellular vesicles. Ann Rev Cell Dev Biol 2014;30:255-89.

37. György B, Szabó TG, Pásztói M, Pál Z, Misják P, et al. Membrane vesicles, current state-of-the-art: emerging role of extracellular vesicles. Cell Mol Life Sci 2011;68:2667-88.

38. Ahn J, Johnstone RM. Origin of a soluble truncated transferrin receptor. Blood 1993;81:2442-51.

39. Zhang J, Li S, Li L, Meng Li M, Guo C, et al. Exosome and exosomal microRNA: trafficking, sorting, and function. Genomics Proteomics Bioinformatics 2015;13:17-24.

40. Costa Verdera H, Gitz-Francois JJ, Schiffelers RM, Vader P. Cellular uptake of extracellular vesicles is mediated by clathrin-independent endocytosis and macropinocytosis. J Control Release 2017;266:100-8.

41. Svensson KJ, Christianson HC, Wittrup A, Bourseau-Guilmain E, Lindqvist E, et al. Exosome uptake depends on ERK1/2-heat shock protein 27 signaling and lipid Raft-mediated endocytosis negatively regulated by caveolin-1. J Biol Chem 2013;288:17713-24.

42. Mulcahy LA, Pink RC, Carter DR. Routes and mechanisms of extracellular vesicle uptake. J Extracell Vesicles 2014;3.

43. Stenmark H. Rab GTPases as coordinators of vesicle traffic. Nat Rev Mol Cell Biol 2009;10:513-25.

44. Sheldon H, Heikamp E, Turley H, Dragovic R, Thomas P, et al. New mechanism for Notch signaling to endothelium at a distance by Delta-like 4 incorporation into exosomes. Blood 2010;116:2385-94.

45. Hargette LA, Bauer NN. On the origin of microparticles: From platelet dust to mediators of intercellular communication. Pulm Circ 2013;3:329-40.

46. Lovren F, Verma S. Evolving role of microparticles in the pathophysiology of endothelial dysfunction. Clin Chem 2013;59:1166-74.

47. Dignat-George F, Boulanger CM. The many faces of endothelial microparticles. Arterioscler Thromb Vasc Biol 2011;31:27-33.

48. Rautou PE, Leroyer AS, Ramkhelawon B, Devue C, Duflaut D, et al. Microparticles from human atherosclerotic plaques promote endothelial ICAM-1-dependent monocyte adhesion and transendothelial migration. Circ Res 2011;108:335-43.

49. Chironi G, Simon A, Hugel B, Del Pino M, Gariepy J, et al. Circulating leukocyte-derived microparticles predict subclinical atherosclerosis burden in asymptomatic subjects. Arterioscle Thromb Vasc Biol 2006;26:2775-80.

50. Wang JM, Wang Y, Huang JY, Yang Z, Chen L, et al. C-Reactive protein-induced endothelial microparticle generation in HUVECs is related to BH4-dependent NO formation J Vasc Res 2007;44:241-8.

51. Habersberger J, Strang F, Scheichl A, Htun N, Bassler N, et al. Circulating microparticles generate and transport monomeric C-reactive protein in patients with myocardial infarction. Cardiovasc Res 2012;96:64-72.

52. Tushuizen ME, Diamant M, Sturk A, Nieuwland R. Cell-derived microparticles in the pathogenesis of cardiovascular disease: friend or foe? Arterioscler Thromb Vasc Biol 2011;31:4-9.

53. Abid Hussein MN, Böing AN, Sturk A, Hau CM, Nieuwland R. Inhibition of microparticle release triggers endothelial cell apoptosis and detachment. Thromb Haemost 2007;98:1096-107.

54. Sayner SL, Choi CS, Maulucci ME, Ramila KC, Zhou C, et al. Extracellular vesicles: another compartment for the second messenger, cyclic adenosine monophosphate. Am J Physiol Lung Cell Mol Physiol 2019;316:L691-700.

55. Deregibus MC, Cantaluppi V, Calogero R, Lo Iacono M, Tetta C, et al. Endothelial progenitor cell derived microvesicles activate an angiogenic program in endothelial cells by a horizontal transfer of mRNA. Blood 2007;110:2440-8.

56. Martin S, Tesse A, Hugel B, Martínez MC, Morel O, et al. Shed membrane particles from T lymphocytes impair endothelial function and regulate endothelial protein expression. Circulation 2004;109:1653-9.

57. Genschmer KR, Russell DW, Lal C, Szul T, Bratcher PE, et al. Activated PMN exosomes: pathogenic entities causing matrix destruction and disease in the lung. Cell 2019;176:113-26.e15.

58. Vats R, Brzoska T, Bennewitz MF, Jimenez MA, Pradhan-Sundd T, et al. Platelet extracellular vesicles drive Inflammasome-IL1 $\beta$ dependent lung injury in sickle cell disease. Am J Respir Crit Care Med 2020;201:33-46.

59. Zahran AM, Elsayh KI, Saad K, Embaby MM, Youssef MAM, et al. Circulating microparticles in children with sickle cell anemia in a tertiary center in upper Egypt. Clin Appl Thromb Hemost 2019;25:1076029619828839. 
60. Holme PA, Orvim U, Hamers MJ, Solum NO, Brosstad FR, et al. Shear-induced platelet activation and platelet microparticle formation at blood flow conditions as in arteries with a severe stenosis. Arterioscler Thromb Vasc Biol 1997;17:646-53.

61. Weber A, Köppen HO, Schrör K. Platelet-derived microparticles stimulate coronary artery smooth muscle cell mitogenesis by a PDGFindependent mechanism. Thromb Res 2000;98:461-6.

62. Oggero S, Austin-Williams S, Norling LV. The contrasting role of extracellular vesicles in vascular inflammation and tissue repair. Front Pharmacol 2019;10:1479.

63. Agouni A, Lagrue-Lak-Hal AH, Ducluzeau PH, Mostefai HA, Draunet-Busson C, et al. Endothelial dysfunction caused by circulating microparticles from patients with metabolic syndrome. Am J Pathol 2008;173:1210-9.

64. Ettelaie C, Su S, Li C, Collier ME. Tissue factor-containing microparticles released from mesangial cells in response to high glucose and AGE induce tube formation in microvascular cells. Microvasc Res 2008;76:152-60.

65. Latifkar A, Hur YH, Sanchez JC, Cerione RA, Antonyak MA. New insights into extracellular vesicle biogenesis and function. J Cell Sci 2019;132:jcs222406.

66. Bebelman MP, Smit MJ, Pegtel DM, Baglio SR. Biogenesis and function of extracellular vesicles in cancer. Pharmacol Ther 2018;188:1-11.

67. Dorai T, Shah A, Summers F, Mathew R, Huang J, et al. NRH:Quinone Oxidoreductase 2 (NQO2) and Glutaminase (GLS) both play a role in large extracellular vesicles (LEV) formation in preclinical LNCaP-C4-2B prostate cancer model of progressive metastasis. Prostate 2018;78:1181-95.

68. Kassem M, Kristiansen M, Abdallah BM. Mesenchymal stem cells: cell biology and potential use in therapy. Basic Clin Pharmacol Toxicol 2004;95:209-14.

69. Li L, Wang R, Jia Y, Rong R, Xu M, et al. Exosomes derived from mesenchymal stem cells ameliorate renal ischemic-reperfusion injurythrough inhibiting inflammation and cell apoptosis. Front Med 2019;6:269.

70. Song YS, Joo HW, Park IH, Shen GY, Lee Y, et al. Bone marrow mesenchymal stem cell-derived vascular endothelial growth factor attenuates cardiac apoptosis via regulation of cardiac miRNA-23a and miRNA-92a in a rat model of myocardial infarction. PLoS One 2017;12:e0179972.

71. Zhou Z, Pan M, Yan C. Mesenchymal stem cells transfer mitochondria into cerebral microvasculature and promote recovery from ischemic stroke. Microvasc Res 2019;123:74-80.

72. Sun Y, Shi H, Yin S, Ji C, Zhang X, et al. Human mesenchymal stem cell derived exosomes alleviate type 2 diabetes mellitus by reversing peripheral insulin resistance and relieving $\beta$-cell destruction. ACS Nano 2018;12:7613-628.

73. Qiu G, Zheng G, Ge M, Wang J, Huang R, et al. Mesenchymal stem cell-derived extracellular vesicles affect disease outcomes via transfer of microRNAs. Stem Cell Res Therap 2018;9:320.

74. Lai RC, Yeo RW, Lim SK. Mesenchymal stem cell exosomes. Semin Cell Dev Biol 2015;40:82-8.

75. Arslan F, Lai RC, Smeets MB, Akeroyd L, Choo A, et al. Mesenchymal stem cell-derived exosomes increase ATP levels, decrease oxidative stress and activate PI3K/Akt pathway to enhance myocardial viability and prevent adverse remodeling after myocardial ischemia/reperfusion injury. Stem Cell Res 2013;10:301-12.

76. Salomon C, Ryan J, Sobrevia L, Kobayashi M, Ashman K, et al. Exosomal signaling during hypoxia mediates microvascular endothelial cell migration and vasculogenesis. PLoS One 2013;8:e68451.

77. Sammour I, Somashekar S, Huang J, Batlahally S, Breton M, et al. The effect of gender on mesenchymal stem cell (MSC) efficacy in neonatal hyperoxia-induced lung injury. PloS One 2016;11:e164269.

78. Zeller CN, Wang Y, Markel TA, Weil B, Abarbanell A, et al. Role of tumor necrosis factor receptor 1 in sex differences of stem cell mediated cardioprotection. Ann Thorac Surg 2009;87:812-9.

79. Wang L, Gu H, Turrentine M, Wang M. Estradiol treatment promotes cardiac stem cell (CSC)-derived growth factors, thus improving CSC-mediated cardioprotection after acute ischemia/reperfusion. Surgery 2014;156:243-52.

80. Matsumoto T, Kubo S, Meszaros LB, Corsi KA, Cooper GM, et al. The influence of sex on the chondrogenic potential of muscle-derived stem cells: implications for cartilage regeneration and repair. Arthritis Rheum 2008;58:3809-19.

81. Mause SF, von Hundelshausen P, Zernecke A, Koenen RR, Weber C. Platelet microparticles: a transcellular delivery system for RANTES promoting monocyte recruitment on endothelium. Arterioscler Thromb Vasc Biol 2005;25:1512-8.

82. Blair LA, Haven AK, Bauer NN. Circulating microparticles in severe pulmonary arterial hypertension increase intercellular adhesion molecule-1 expression selectively in pulmonary artery endothelium. Respir Res 2016;17:133.

83. Nadaud S, Poirier O, Girerd B, Blanc C, Montani D, et al. Small platelet microparticle levels are increased in pulmonary arterial hypertension. Eur J Clin Invest 2013;43:64-71.

84. Diehl P, Aleker M, Helbing T, Sossong V, Germann M, et al. Increased platelet, leukocyte and endothelial microparticles predict enhanced coagulation and vascular inflammation in pulmonary hypertension. J Thromb Thrombolysis 2011;31:173-9.

85. Amabile N, Heiss C, Chang V, Angeli FS, Damon L, et al. Increased CD62e (+) endothelial microparticle levels predict poor outcome in pulmonary hypertension patients. J Heart Lung Transplant 2009;28:1081-6.

86. Tual-Chalot S, Guibert C, Muller B, Savineau JP, Andriantsitohaina R, et al. Circulating microparticles from pulmonary hypertensive rats induce endothelial dysfunction. Am J Respir Crit Care Med 2010;182:261-8.

87. Bakouboula B, Morel O, Faure A, Zobairi F, Jesel L, et al. Procoagulant membrane microparticles correlate with the severity of pulmonary arterial hypertension. Am J Respir Crit Care Med 2008;177:536-43.

88. Kosanovic D, Deo U, Gall H, Selvakumar B, Herold S, et al. Enhanced circulating levels of CD3 cells-derived extracellular vesicles in different forms of pulmonary hypertension. Pulm Circ 2019;9:2045894019864357.

89. Zhao L, Luo H, Li X, Li T, He J, et al. Exosomes derived from human pulmonary artery endothelial cells shift the balance between 
proliferation and ppoptosis of smooth muscle cells. Cardiology 2017;137:43-53.

90. Jenkins NT, Padilla J, Boyle LJ, Credeur DP, Laughlin MH, et al. Disturbed blood flow acutely induces activation and apoptosis of the human vascular endothelium. Hypertension 2013;61:615-21.

91. Lin ZB, Ci HB, Li Y, Cheng TP, Liu DH, et al. Endothelial microparticles are increased in congenital heart diseases and contribute to endothelial dysfunction. J Transl Med 2017;15:4.

92. Smadja DM, Gaussem P, Mauge L, Lacroix R, Gandrille S, et al. Comparison of endothelial biomarkers according to reversibility of pulmonary hypertension secondary to congenital heart disease. Ped Cardiol 2010;31:657-62.

93. Sirois I, Raymond MA, Brassard N, Cailhier JF, Fedjaev M, et al. Caspase-3-dependent export of TCTP: a novel pathway for antiapoptotic intercellular communication. Cell Death Differ 2011;18:549-62.

94. Lavoie JR, Ormiston ML, Perez-Iratxeta C, Courtman DW, Jiang B, et al. Proteomic analysis implicates translationally controlled tumor protein as a novel mediator of occlusive vascular remodeling in pulmonary arterial hypertension. Circulation 2014;129:2125-35.

95. Ferrer E, Dunmore BJ, Hassan D, Ormiston ML, Moore S, et al. A potential role for exosomal translationally controlled tumor protein export in vascular remodeling in pulmonary arterial hypertension. Am J Respir Cart Care Med 2018;59:467-78.

96. Deng L, Blanco FJ, Stevens H, Lu R, Caudrillier A, et al. MicroRNA-143 activation regulates smooth muscle and endothelial cell crosstalk in pulmonary arterial hypertension. Circ Res 2015;117:870-83.

97. Banz Y, Beldi G, Wu Y, Atkinson B, Usheva A, et al. CD39 is incorporated into plasma microparticles where it maintains functional properties and impacts endothelial activation. Br J Haematol 2008;142:627-37.

98. Helenius MH, Vattulainen S, Orcholski M, Aho J, Komulainen A, et al. Suppression of endothelial CD39/ENTPD1 is associated with pulmonary vascular remodeling in pulmonary arterial hypertension. Am J Physiol Lung Cell Mol Physiol 2015;308:L1046-57.

99. Visovatti SH, Hyman MC, Bouis D, Neubig R, McLaughlin VV, et al. Increased CD39 nucleotidase activity on microparticles from patients with idiopathic pulmonary arterial hypertension. PLoS One 2012;7:e40829.

100. Dereddy N, Huang J, Erb M, Guzel S, Wolk JH, et al. Associated inflammation or increased flow-mediated shear stress, but not the pressure alone disrupts endothelial caveolin-1 in infants with pulmonary hypertension. Pulm Circ 2012;2:492-500.

101. Amabile N, Heiss C, Real WM, Minasi P, McGlothlin D, et al. Circulating endothelial microparticle levels predict hemodynamic severity of pulmonary hypertension. Am J Respir Crit Care Med 2008:177:1268-75.

102. Murakami K, Mathew R, Farahami R, Peng H, Olson SC, et al. Smurf-1 ubiquitin ligase causes downregulation of BMP recptors and is induced in monocrotaline and hypoxiamodles of pulmonary arterial hypertension. Exp Biol Med 2010;235:805-13.

103. Atkinson C, Stewart S, Upton PD, Machado R, Thomson JR, et al. Primary pulmonary hypertension is associated with reduced pulmonary vascular expression of type II bone morphogenetic protein receptor. Circulation 2002;105:1672-8.

104. Oliveira SD, Castellon M, Chen J, Bonini MG, Gu X, et al. Inflammation-induced caveolin-1 and BMPRII depletion promotes endothelial dysfunction and TGF- $\beta$-driven pulmonary vascular remodeling. Am J Physiol Lung Cell Mol Physiol 2017;312:L760-71.

105. Oliveira SDS, Chen J, Castellon M, Mao M, Raj JU, et al. Injury-induced shedding of extracellular vesicles depletes endothelial cells of cav-1 (Caveolin-1) and enables TGF- $\beta$ (transforming growth factor- $\beta$ )-dependent pulmonary arterial hypertension. Arterioscler Thromb Vasc Biol 2019;39:1191-202.

106. Patel HH, Zhang S, Murray F, Suda RY, Head BP, et al. Increased smooth muscle cell expression of caveolin-1 and caveolae contribute to the pathophysiology of idiopathic pulmonary arterial hypertension. FASEB J 2007;21:2970-9.

107. de la Cuesta F, Passalacqua I, Rodor J, Bhushan R, Denby L, et al. Extracellular vesicle cross-talk between pulmonary artery smooth muscle cells and endothelium during excessive TGF- $\beta$ signalling: implications for PAH vascular remodeling. Cell Communication Signaling 2019;17:143.

108. Welch-Reardon KM, Wu N, Hughes CC. A role for partial endothelial-mesenchymal transitions in angiogenesis? Areterioscler Thromb Vasc Biol 2015;35:303-8.

109. Zhu L, Xiao R, Zhang X, Lang Y, Liu F, et al. Supermine on endothelial extracellular vesicles mediates smoking-induced pulmonary hypertension partially through calcium-sensing receptor. Arterioscler Thromb Vasc Biol 2019;39:482-95.

110. Wang P, Zhang C, Li J, Luo L, Zhang S, et al. Adipose-derived mesenchymal stromal cells improve hemodynamic function in pulmonary arterial hypertension: identification of microRNAs implicated in modulating endothelial function Cytotherapy 2019;21:416-27.

111. Kanki-Horimoto S, Horimoto H, Mieno S, Kishida K, Watanabe F, et al. Implantation of mesenchymal stem cells overexpressing endothelial nitric oxide synthase improves right ventricular impairments caused by pulmonary hypertension. Circulation 2006;114:1181-5.

112. Liang OD, Mitsialis SA, Chang MS, Vergadi E, Lee C, et al. Mesenchymal stromal cells expressing heme oxygenase-1 reverse pulmonary hypertension. Stem Cells 2011;29:99-107.

113. Takemiya K, Kai H, Yasukawa H, Tahara N, Kato S, et al. Mesenchymal stem cell-based prostacyclin synthase gene therapy for pulmonary hypertension rats. Basic Res Cardiol 2010;105:409-17.

114. Luo L, Zheng W, Lian G, Chen H, Li L, et al. Combination treatment of adipose-derived stem cells and adiponectin attenuates pulmonary arterial hypertension in rats by inhibiting pulmonary arterial smooth muscle cell proliferation and regulating the AMPK/BMP/Smad pathway. Int J Mol Med 2018;41:51-60.

115. Umar S, de Visser YP, Steendijk P, Schutte CI, Laghmani EH, et al. Allogenic stem cell therapy improves right ventricular function by improving lung pathology in rats with pulmonary hypertension. Am J Physiol Heart Circ Physiol 2009;297:H1606-16.

116. Liu K, Liu R, Cao G, Sun H, Wang X, et al. Adipose-derived stromal cell autologous transplantation ameliorates pulmonary arterial hypertension induced by shunt flow in rat models. Stem Cells Dev 2011;20:1001-10.

117. Tan R, Li J, Peng X, Zhu L, Cai L, et al. GAPDH is critical for superior efficacy of female bone marrow-derived mesenchymal stem cells on pulmonary hypertension. Cardiovasc Res 2013;100:19-27. 
118. Crisostomo PR, Markel TA, Wang M, Lahm T, Lillemoe KD, et al. In the adult mesenchymal stem cell population, source gender is a biologically relevant aspect of protective power. Surgery 2007;142:215-21.

119. Aliotta JM, Pereira M, Wen S, Dooner MS, Del Tatto M, et al. Exosomes induce and reverse monocrotaline-induced pulmonary hypertension in mice. Cardiovasc Res 2016;110:319-30.

120. Chen JY, An R, Liu ZJ, Wang JJ, Chen SZ, et al. Therapeutic effects of mesenchymal stem cell-derived microvesicles on pulmonary arterial hypertension in rats. Acta Pharmacol Sin 2014;35:1121-8.

121. Liang X, Zhang L, Wang S, Han Q, Zhao RC. Exosomes secreted by mesenchymal stem cells promote endothelial cell angiogenesis by transferring miR-125a. J Cell Sci 2016;129:2182-9.

122. Liu Z, Liu J, Xiao M, Wang J, Yao F, et al. Mesenchymal stem cell-derived microvesicles alleviate pulmonary arterial hypertension by regulating renin-angiotensin system. J Am Soc Hypertens 2018;12:470-8.

123. Liu R, Shen H, Ma J, Sun L, Wei M. Extracellular vesicles derived from adpose mesenchymal stem cells regulate the phenotype of smooth muscle cells to limit intimal hyperplasia. Cardiovasc Drug Therapy 2016;30:111-8.

124. Lee C, Mitsialis SA, Aslam M, Vitali SH, Vergadi E, et al. Exosomes mediate the cytoprotective action of mesenchymal stromal cells on hypoxia-induced pulmonary hypertension. Circulation 2012;126:2601-11.

125. Klinger JR, Pereira M, Del Tatto M, Brodsky AS, Wu KQ, et al. Mesenchymal stem cell extracellular vesicles reverse sugen/hypoxia pulmonary hypertension in rats. Am J Respir Cell Mol Biol 2019; Epub ahead of print. doi: org/10.1165/rcmb.2019-0154OC

126. Hogan SE, Rodriguez-Salazar MP, Cheadle J, Glenn R, Medrano, et al. Mesenchymal stromal cell-derived exosomes improve mitochondrial health in pulmonary arterial hypertension. Am J Physiol Lung Cell Mol Physiol 2019;316:L723-37.

127. Hansmann G, Fernandez-Gonzalez A, Aslam M, Vitali SH, Martin T, et al. Mesenchymal stem cell-mediated reversal of bronchopulmonary dysplasia and associated pulmonary. Pulm Circ 2012;2:170-81.

128. Chang YS, Ahn SY, Yoo HS, Sung SI, Choi SJ, et al. Mesenchymal stem cells for bronchopulmonary dysplasia: phase 1 dose-escalation clinical trial. J Ped 2014; 164:966-72. 